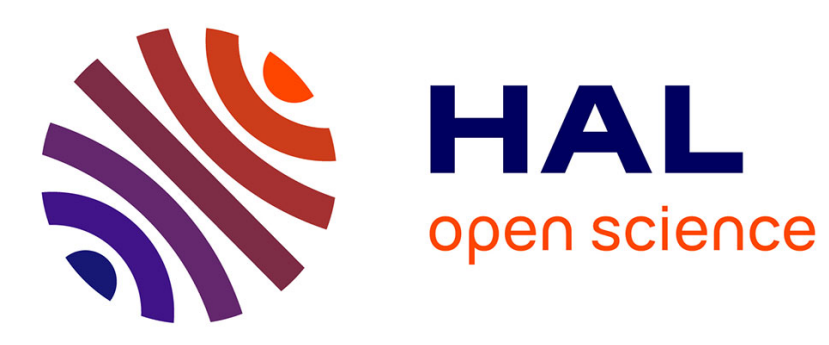

\title{
Strain engineering in III-V photonic components through structuration of SiN x films
}

Brahim Ahammou, Aysegul Abdelal, Jean-Pierre Landesman, Christophe

Levallois, Peter Mascher

\section{To cite this version:}

Brahim Ahammou, Aysegul Abdelal, Jean-Pierre Landesman, Christophe Levallois, Peter Mascher. Strain engineering in III-V photonic components through structuration of SiN x films. Journal of Vacuum Science \& Technology B, Nanotechnology and Microelectronics, 2022, 40 (1), pp.012202. 10.1116/6.0001352 . hal-03481497

\section{HAL Id: hal-03481497 \\ https://hal.science/hal-03481497}

Submitted on 15 Dec 2021

HAL is a multi-disciplinary open access archive for the deposit and dissemination of scientific research documents, whether they are published or not. The documents may come from teaching and research institutions in France or abroad, or from public or private research centers.
L'archive ouverte pluridisciplinaire $\mathbf{H A L}$, est destinée au dépôt et à la diffusion de documents scientifiques de niveau recherche, publiés ou non, émanant des établissements d'enseignement et de recherche français ou étrangers, des laboratoires publics ou privés. 


\title{
Strain engineering in III-V photonic components through structuration of $\mathrm{SiN}_{\mathrm{x}}$ films
}

\author{
Running title: Strain engineering in III-V photonic components \\ Running Authors: Ahammou et al.
}

\author{
Brahim Ahammou 1,2,a), Aysegul Abdelal ${ }^{2}$, Jean-Pierre Landesman ${ }^{1}$, Christophe \\ Levallois ${ }^{1}$ and Peter Mascher ${ }^{2}$ \\ ${ }^{1}$ Univ Rennes, INSA Rennes, CNRS, Institut FOTON-UMR 6082, F-35000 Rennes, France \\ ${ }^{2}$ Department of Engineering Physics and Centre for Emerging Device Technologies, McMaster \\ University, Hamilton, ON, L8S 4L8, Canada
}

\section{a) Electronic mail: brahim.ahammou@univ-rennes1.fr}

We describe work to quantify the effects of structured dielectric thin films, such as $\mathrm{SiN}_{\mathrm{x}}$, at the surface of III-V semiconductors, in terms of strain engineering with applications to photonic components such as waveguides and lasers. We show that the strain in the semiconductor can be engineered by controlling the stress in the dielectric thin film by tuning its deposition process. In the first part of this study, we describe how we can control the amount of this built-in mechanical stress, in the case of $\mathrm{SiN}_{\mathrm{x}}$, over a large range, from highly tensile (300 MPa) to highly compressive (-800 MPa), using two different kinds of plasma-enhanced chemical vapor deposition reactors: a standard capacitively-coupled reactor with radio-frequency excitation and an electron cyclotron resonance reactor with micro-wave excitation. We focused on characterizing and understanding these thin films' optical and chemical bonding properties through spectroscopic ellipsometry and Fourier transform infrared spectroscopy. We have also studied their mechanical properties experimentally using the wafer curvature measurement technique, microstructure fabrication, and nano-indentation measurements. In the second part, we show accurate 
measurements of the strain distribution induced within GaAs wafers when such thin films are structured in the shape of elongated stripes of variable width, using standard optical lithography and plasma etching. For this, we map the anisotropic deformation, measuring the degree of polarization of the spectrally integrated photoluminescence (PL) generated within GaAs by excitation with a red laser. PL from the bulk cubic semiconductors such as $\mathrm{GaAs}$ and $\mathrm{InP}$ is unpolarized, whereas anisotropic strain produces some degree of polarization. These maps were measured either from the semiconductor surface or from cleaved cross-sections. They provide a detailed and complete image of the crystal deformation in the vicinity of the structured stressor film. Finally, we have performed some finite element simulations trying to reproduce the experimental maps. This investigation covering the different steps, including control of the built-in stress within the $\mathrm{SiN}_{\mathrm{x}}$ thin films, mapping of the anisotropic deformation field generated within the semiconductor beneath the structured films, and numerical simulation of these effects, allows us to propose a set of recipes that can be employed for strain engineering of III-V photonic components. Our simulation scheme is helpful for the design of the photonic components, e.g., to predict the local changes in the refractive index due to the photo-elastic effect. 


\section{INTRODUCTION}

Strain engineering in photonic devices appears in different areas of investigation. Examples are the control of optical waveguides ${ }^{1-3}$ during their fabrication, the optimization of the performance of diode lasers through the introduction of epitaxial strain in the quantum well (QW) active layer ${ }^{4}$, or the monitoring of the perturbation in laser diode operation induced by mechanical stress resulting from the packaging of a laser diode chip ${ }^{5}$. Strain in semiconductor materials such as $\mathrm{Si}, \mathrm{GaAs}$, or $\mathrm{InP}$ and their compounds also modifies their dielectric response ${ }^{6}$. When the distortion is small enough, a linear relationship approximation between the change in the inverse dielectric function and the strain can be assumed, described by the photo-elasticity tensor. This approach has been widely used to describe the effect of strain on the refractive index at energies smaller than the band gap ${ }^{1}$. Because of their cubic crystal symmetry in the un-deformed state, $\mathrm{Si}$, GaAs, and InP are normally characterized by a single isotropic refractive index. Any strain that is not hydrostatic modifies the refractive index into a matrix with some degree of anisotropy.

Consequently, strain can introduce materials-related local birefringence, which may combine with the geometrical birefringence in a waveguide ${ }^{2}$. Strain in a waveguide can change the geometrical properties of the optical mode, the cutoff thickness, change a single-mode waveguide into multi-mode, change the waveguide's polarization properties, and affect its propagation losses ${ }^{1}$. Built-in strain in epitaxial QWs is generally incorporated during the growth of the active layer of semiconductor lasers. However, in general, this strain cannot be considered small enough for the linear relationship to hold ${ }^{4}$. To account for the effect of strain in this regime, for energies above the bandgap, a calculation of the modifications of both the valence and the conduction bands must be performed ${ }^{4}$. Strain in QWs is used to tune the optoelectronic characteristics such as gain and the polarization of 
the stimulated emission ${ }^{4}$. Strain resulting from the packaging of a laser diode chip may affect both the optical transitions within the QW and the refractive index of the waveguide.

Two "opposite" strategies for strain engineering, considering the effects of the mechanical strain on the photonic device, can be pursued. In the first strain engineering strategy, strain is considered a problem, and efforts are made to minimize the presence of strain in order to avoid any deleterious effect. In the second strategy, strain is considered a means to control the material's properties and is deliberately introduced in the semiconductor material to control its local properties and thus enhance some performance(s) of the photonic device.

The possible origins of strain in photonic devices can roughly be divided into three classes:

1. Strain caused by the presence of a layer or layers of material(s) with different mechanical properties at the surface of the device: for example, metal or dielectric layers. These are, in general, deposited above room temperature. This induces a strain field within the semiconductor because these layers possess an intrinsic built-in strain and because of the differential thermal expansion. This type of strain can be deleterious to any kind of photonic device if not controlled. Still, it can also be used to tune the local optical properties of the semiconductor through the "stressor" concept ${ }^{7}$.

2. Epitaxial strain in the device's active layer, for example, in the QW of a semiconductor laser. This strain often is controlled during the epitaxial growth and is used to optimize the device's performance.

3. Strain occurring during the back-end or packaging part of the fabrication process. In general, this is caused by the combination of different materials in the photonic module or the package. The magnitude should always be monitored to assess the device reliability, but measurements can be more difficult at this stage. 
This paper describes our investigations on the effects of $\mathrm{SiN}_{\mathrm{x}}$ stressor structures on the strain profiles in their underlying GaAs substrates. Such stressor structures have been used to fabricate photo-elastic waveguides in these materials ${ }^{3,8}$ as well as in Si-based materials ${ }^{9,10}$. The first stage of our study deals with the control of the built-in stress in $\mathrm{SiN}_{\mathrm{x}}$ thin films obtained by plasma-enhanced chemical vapor deposition (PECVD). Numerous publications have already covered this field ${ }^{11}$; however, it is important for us to describe how we control this starting point of the built-in stress in our $\mathrm{SiN}_{\mathrm{x}}$ thin films by tuning some of the PECVD process parameters. The built-in stress was deduced from wafer curvature measurements. The optical and chemical bonding properties of the thin films were assessed from variable angle spectroscopic ellipsometry (VASE) and Fourier transformed infra-red spectroscopy (FTIR). The mechanical properties of the thin films (Young's modulus) were estimated from nano-indentation measurements and observations of the shape of test structures after partial release of the films from their substrate. In the second stage, the $\mathrm{SiN}_{\mathrm{x}}$ thin films were structured into elongated stripes by optical lithography and etching. This generates a strain field in the underlying substrate with strong spatial modulation, especially near the stripe edges. This strain field was determined experimentally using spatially resolved photoluminescence (PL) measurements. The specificity of our PL set-up is the analysis of the degree of polarization (DOP) of the PL, which was shown to provide a unique insight into the anisotropic strain ${ }^{5,12}$. This technique produces detailed maps of the anisotropic strain field by scanning the laser beam, either from the top surface or the cleaved surface below a $\mathrm{SiN}_{\mathrm{x}}$ stripe. In the third stage, we propose some schemes for the numerical simulation, using finite element tools, of the strain fields described previously. The simulation results are compared with the measurements. 
We conclude by a discussion in which we emphasize the importance of controlling all these steps of the overall strategy in order to better predict the final specifications of photonic device such as passive waveguides fabricated using the concept of strain engineering.

Various issues discussed in our work have already been addressed in other papers ${ }^{1-}$ ${ }^{3,12-14}$. A small fraction of these papers deals with the complete sequence of steps that must be covered to fully monitor the effect of strain on a specific photonic device ${ }^{3}$. Our main objective is to show how important it is to couple the best possible knowledge on controlling the built-in stress in the stressor layers with the most accurate strain measurement methods to develop efficient strain engineering techniques for photonic devices based on III-V semiconductors. 


\section{EXPERIMENTAL}

\section{A. Plasma enhanced chemical vapor deposition of $\operatorname{SiN}_{x}$ thin films}

Amorphous $\mathrm{SiN}_{\mathrm{x}}$ thin films were deposited on $\mathrm{Si}$ and $\mathrm{Si}$-doped GaAs substrates using a commercial Corial-D250 capacitively coupled plasma (CCP) and a specially designed electron cyclotron resonance (ECR) PECVD reactors. The CCP reactor operates with radiofrequency (RF) power at $13.56 \mathrm{MHz}$, while the ECR system uses $2.45 \mathrm{GHz}$ microwave (MW) frequency to yield the electron cyclotron resonance condition at $875 \mathrm{G}$, provided by an electromagnet. The details of the ECR PECVD system were presented in a previous study ${ }^{15}$. Before deposition, the substrates were dipped in $\mathrm{HF}: \mathrm{H}_{2} \mathrm{O}(1: 20)$ for one minute to remove the native oxide layer.

For the thin films deposited with the $\mathrm{CCP}$ reactor, $\mathrm{SiH}_{4}, \mathrm{Ar}, \mathrm{NH}_{3}$, and $\mathrm{N}_{2}$ were used as gas precursors, and the flow rates were kept constant at 20,400, 50, and $250 \mathrm{sccm}$, respectively, and the total pressure was equal to 1500 mTorr. The substrate heater temperature was set to $280^{\circ} \mathrm{C}$ for all samples, and the $\mathrm{RF}$ power was varied from 20 to 170 $\mathrm{W}$. The deposition rates ranged from around 50 to $90 \mathrm{~nm} \cdot \mathrm{min}^{-1}$.

In the ECR PECVD reactor, $\mathrm{SiH}_{4}, \mathrm{Ar}$, and $\mathrm{N}_{2}$ were used as gas precursors and the flow rates were kept constant at 2.8, 2.4, and $10.8 \mathrm{sccm}$, respectively. The total pressure was $1.7 \mathrm{mTorr}$. The substrate heater temperature was set to $350^{\circ} \mathrm{C}$, which corresponds to $120^{\circ} \mathrm{C}$ at the sample surface, and the MW power coupled to the plasma was adjusted from 400 to $600 \mathrm{~W}$. The deposition rates varied from around 1 to about $1.8 \mathrm{~nm} \cdot \mathrm{min}^{-1}$.

Si substrates were used for the systematic study of the optical and mechanical properties of the $\mathrm{SiN}_{\mathrm{x}}$ thin films as a function of the deposition conditions. However, for 
the second stage of this study (described in part C), we had to grow the $\mathrm{SiN}_{\mathrm{x}}$ thin films onto GaAs substrates and process these thin films into elongated stripes. Thin films on GaAs were deposited using the same reactor conditions as for the growth on Si substrates. We measured the built-in stress in these thin films deposited on GaAs substrates using the wafer curvature measurement method. Still, we did not perform any systematic study, contrary to what was done for Si substrates.

\section{B. Characterization of the as-deposited thin films}

\section{Built-in stress from wafer curvature measurement}

We evaluated the built-in stress in the deposited thin films using the standard method of wafer curvature measurement in the framework of the Stoney model ${ }^{16}$. The curvature was measured before and after the deposition using a Tencor - Alpha Step 200 Stylus profilometer. Variation of the RF power injected into the CCP reactor yields variable residual stress from tensile (+ $300 \mathrm{MPa})$ to compressive (- $400 \mathrm{MPa})$, as illustrated in fig. 1. The higher the deposition power, the more compressively strained the film. Figure 1 also shows that the ECR PECVD $\mathrm{SiN}_{\mathrm{x}}$ films were all compressively strained, and higher injected microwave power yields less compressively strained films.

Figure 1: Built-in stress versus excitation power for (a) $500 \mathrm{~nm} \mathrm{SiN}$ films deposited within the CCP reactor and (b) $500 \mathrm{~nm} \mathrm{SiN}$ films deposited within the ECR reactor. Substrate: Si. 
As shown in fig. 1, we can obtain thin $\mathrm{SiN}_{\mathrm{x}}$ films with built-in stress between about $-790 \mathrm{MPa}$ (compressive) and + $300 \mathrm{MPa}$ (tensile) by only modifying the deposition power of the PECVD systems.

\section{Spectroscopic ellipsometry}

We used an M-2000U ultraviolet-visible J.A. Woollam variable angle spectroscopic ellipsometer (VASE) to measure thin films' absorption and refractive index. All results described here were obtained at a $70^{\circ}$ incident angle. Subsequently, we evaluated the refractive index and the absorption of the thin films as a function of the wavelength using the Tauc-Lorentz model ${ }^{17,18}$. The optical bandgaps of the films can be extracted from the Tauc plots shown in Figure 2 (b).

Figure 2: Effective refractive index at $632 \mathrm{~nm}$ (a) and Tauc plots derived from the optical absorption measurements (b) of the $500 \mathrm{~nm} \mathrm{SiN}$ films deposited within the CCP reactor. Substrates: Si.

Figure 2 (a) shows only a slight increase in the refractive index $(1.88<\mathrm{n}<1.89)$ as a function of the deposition power for the $\mathrm{SiN}_{\mathrm{x}}$ films deposited within the CCP reactor, while fig. 2 (b) shows that the optical band gap increases significantly from $3 \mathrm{eV}$ to $4 \mathrm{eV}$ with increasing deposition power.

\section{Fourier transform infrared spectroscopy}


The chemical bond vibration modes of the $\mathrm{SiN}_{\mathrm{x}}$ films were analyzed by Fourier Transform Infrared Spectroscopy (FTIR). We performed the measurements using a BRUKER Hyperion 3000. The $\mathrm{SiN}_{\mathrm{x}}$ films deposited in the CCP reactor were $1.5 \mu \mathrm{m}$ thick on double-side polished (DSP) Si substrates, while the samples fabricated in the ECR reactor have a thickness of $500 \mathrm{~nm}$. All measurements were performed under ambient conditions, and the observed absorption range was from 300 to $4000 \mathrm{~cm}^{-1}$.

As discussed in ${ }^{19}$, the typical vibration modes of $\mathrm{SiN}_{\mathrm{x}}$ are associated with the $\mathrm{Si}-\mathrm{N}$ bonds in the stretching vibration mode at about $830-890 \mathrm{~cm}^{-1}$ and the $\mathrm{N}-\mathrm{H}$ bonds in the bending and the stretching vibration modes at $1175 \mathrm{~cm}^{-1}$ and $3335 \mathrm{~cm}^{-1}$, respectively.

The FTIR spectra of $\mathrm{SiN}_{\mathrm{x}}$ deposited in the CCP reactor using different RF powers $(50 \mathrm{~W}, 80 \mathrm{~W}, 130 \mathrm{~W})$ are shown in fig. 3.

Figure 3: FTIR spectra of $1.5 \mu \mathrm{m} \mathrm{SiN}$ films deposited by the CCP reactor at 50, 80, and $130 \mathrm{~W}$ deposition power: Substrate: $\mathrm{Si}$. (a) FTIR absorption range for $\mathrm{SiN}_{\mathrm{x}}$ from 300 to $4000 \mathrm{~cm}^{-1}$, (b) Si-H absorption peak intensity, (c) N-H absorption peak intensity.

We notice in fig. 3 (b) that the intensity of the Si-H absorption peaks increases when the deposition power increases from 50 to $130 \mathrm{~W}$, whereas the absorption intensity for Si$\mathrm{N}$ bonds remains virtually constant (Fig. 3 (a)).

Figure 4. FTIR Spectra of $500 \mathrm{~nm} \mathrm{SiN}$ thin films deposited in the ECR reactor at different deposition powers ( $400 \mathrm{~W}, 500 \mathrm{~W}, 600 \mathrm{~W})$. Substrate: Si. 
Contrary to the above, the FTIR spectra of $\operatorname{SiN}_{x}$ thin films deposited within the ECR reactor show virtually constant absorption in the $\mathrm{Si}-\mathrm{H}$ and $\mathrm{N}-\mathrm{H}$ bonds when the deposition power changes (see Figure 4).

\section{Nano-indentation and other investigations of the mechanical}

\section{properties}

Mechanical properties of $\mathrm{SiN}_{\mathrm{x}}$ materials have been intensely studied ${ }^{13,20}$ in relation to their extensive use in a broad range of applications such as Micro Electro Mechanical Systems (MEMS), microelectronics, and photonic devices. In the present study, Young's modulus and hardness were determined by nano-indentation measurements using a NanoTest Vantage instrument, with a maximum load of $1 \mathrm{mN}$ and an average penetration depth through the samples of $50 \mathrm{~nm}$. The recommended penetration depth ${ }^{21}$ is $10 \%$ of the film thickness to avoid substrate effects and obtain more accurate results. The force load versus the penetration depth is recorded. Young's modulus and hardness are calculated from the load-depth curves using Oliver and Pharr's analysis ${ }^{21}$.

Figure 5: Young's modulus and hardness from nano-indentation for $500 \mathrm{~nm} \mathrm{SiN}_{\mathrm{x}}$ films deposited in the CCP reactor with $130 \mathrm{~W}$ RF power (compressive built-in stress: $300 \mathrm{MPa})$. Substrate: Si.

Figure 5 shows that the Young's modulus and the thin film hardness increase with the RF power. 
We have also used doubly clamped microbeams fabricated from films with wellcontrolled built-in compressive stress to evaluate some of the elastic properties of these thin films.

Figure 6: Cross-sectional schematic view of the process steps for the fabrication of a $\mathrm{SiN}_{\mathrm{x}}$ microbeam on top of a $\mathrm{Si}$ substrate using $\mathrm{SiN}_{\mathrm{x}}$ compressively strained films.

Figure 6 shows a schematic of the process for the fabrication of a $\mathrm{SiN}_{\mathrm{x}}$ microbeam. After etching of the dielectric thin film into $15 \mu$ m wide stripes, we release the $\mathrm{SiN}_{\mathrm{x}}$ microbeams from the Si substrate using wet etching with tetramethylammonium hydroxide (TMAH) ( $5 \%$ solution at $85 \mathrm{C}^{\circ}$ ). TMAH is known to produce anisotropic etching of Si. Figure 7 shows a scanning electron microscope (SEM) image of such a microbeam obtained after etching and releasing a $\mathrm{SiN}_{\mathrm{x}}$ film deposited on $\mathrm{Si}$ by PECVD with initial compressive builtin stress of $-300 \mathrm{MPa}$.

Figure 7: SEM image of a micro-beam fabricated from a $\mathrm{SiN}_{\mathrm{x}}$ film deposited on a Si substrate using a CCP reactor with $130 \mathrm{~W}$ RF power (compressive built-in stress: -300 $\mathrm{MPa})$

We used the micro-beam buckling test to evaluate the Young's modulus of $\mathrm{SiN}_{\mathrm{x}}$ thin films whose built-in residual (compressive) stress was previously deduced from wafer curvature measurements. We took the value of the Poisson's ratio from the literature ${ }^{22}(v=0.23)$. The procedure is described below: 
First, we assume that the micro-beam has a uniform compressive residual stress $\sigma$ along its entire length before it is released from the substrate. Once released from the substrate, the micro-beams regain their equilibrium length without mechanical stress and tend to bend perpendicular to the compression plane; thus, a buckling phenomenon is observed. The deformation of the microbeam was measured with a commercial Olympus confocal microscope with a blue laser diode to get as high an accuracy as possible on the measurement of the vertical profile of the released micro-beams $( \pm 50 \mathrm{~nm})$. Then, a curve fitting of the data was performed to extract the elongation of the micro-beams $\Delta L / L_{0}$, where $L_{0}$ is the initial length of the micro-beam before the release. This measured elongation can be correlated to Young's modulus E by the following formula:

$$
E \approx \sigma_{\text {stoney }}\left(\frac{1}{1-v} \frac{\Delta L}{L_{0}}\right)^{-1}
$$

We assume that the elongation of the microbeam is induced only by the magnitude of the built-in compressive stress. We have performed these measurements on the compressive $\mathrm{SiN}_{\mathrm{x}}$ thin films and calculated the Young's modulus values using a Poisson's ratio of $0.23^{22}$. Figure 8 shows the Young's modulus of compressively strained $\mathrm{SiN}_{\mathrm{x}}$ films using the microbeams technique and nano-indentation.

Figure 8: Young's modulus of $\mathrm{SiN}_{\mathrm{x}}$ films with compressive built-in stress deposited on Si using a CCP reactor

The Young's modulus values deduced from nano-indentation measurements appear higher than those deduced from the microbeams elongation, except for thick films. We can notice a slight increase in Young's modulus for the nano-indentation measurement while Young's 
modulus measured from the microbeams elongation seem unchanged and slightly decrease for large compressive stresses.

\section{Mapping of the anisotropic strain by measurement of the degree of polarization of the photoluminescence}

We measured the degree of polarization of the PL (DOP-PL) to locally investigate the anisotropic part of the strain tensor. The DOP-PL results from the anisotropic deformation of a nominally cubic crystal. More precisely, the DOP-PL signal is related to the difference in the normal strain coefficients with two orthogonal directions in the plane perpendicular to the laser beam used for these measurements. We define the DOP of PL for material under study as

$$
D O P_{y}=\frac{L_{x}-L_{z}}{L_{x}+L_{z}}(2)
$$

where $L_{x}$ and $L_{z}$ are the measured irradiance for light polarized along the $\mathrm{x}$ and $\mathrm{z}$ direction, respectively. In equation 2 , "y" denotes the propagation direction for both the excitation laser beam and the detected PL signal beam, "x" and "z" are two directions in the perpendicular plane. We refer the reader to ${ }^{23}$ for the experimental details as well as the associated formalism. The principle of the DOP-PL measurement is to excite the PL at room temperature, using a $635 \mathrm{~nm}$ red laser focused on the surface of the sample. Thus, the substrate emits PL radiation polarized according to the stress state of the semiconductor. Note that the DOP-PL technique uses the spectrally integrated PL signal.

After deposition on full (100) GaAs wafers, the built-in residual stress in the $\mathrm{SiN}_{\mathrm{x}}$ thin films was determined from wafer curvature measurements. All the $\mathrm{SiN}_{\mathrm{x}}$ thin films used in this part were fabricated using the $\mathrm{CCP}$ reactor, with deposition conditions identical to 
those investigated previously for Si substrates. Note that the measured built-in stress was relatively similar (+/- $30 \mathrm{MPa}$ ) for films deposited under identical conditions on GaAs and Si substrates. Using the Stoney model ${ }^{24}$, we verified that the measured built-in stresses were scaled correctly with Young's modulus of GaAs and Si values. The small difference observed can be related to the thermal component of the residual stress, which is different because the coefficients of thermal expansion of the two substrates are different. $\mathrm{SiN}_{\mathrm{x}}$ films were subsequently patterned by photolithography and etched by reactive ion etching using an $\mathrm{SF}_{6}$ plasma. We performed DOP-PL measurements to map the magnitude and the distribution of residual mechanical stresses in GaAs (100) and InP (100) substrates induced by the presence of strained $\mathrm{SiN}_{\mathrm{x}}$ stripes on the top. Only results for GaAs are described and discussed in this paper for simplicity. However, results for $\mathrm{InP}$ were qualitatively similar.

Figure 9: Geometry of a $\mathrm{SiN}_{\mathrm{x}}$ stripe on an $\mathrm{InP}$ or GaAs (100) substrate

The DOP-PL as measured on the cross-section is related to the strain by the following formula ${ }^{5}$ (see fig. 9 for the $\mathrm{x}, \mathrm{y}$, and $\mathrm{z}$ axes):

$$
D O P_{y}=-C \cdot\left(\varepsilon_{x x}-\varepsilon_{z z}\right)
$$

where $\left(\varepsilon_{x x}-\varepsilon_{z z}\right)$ denotes the difference in the normal components of strain.

For the top surface measurements, the DOP formula is:

$$
D O P_{z}=-C \cdot\left(\varepsilon_{x x}-\varepsilon_{y y}\right)
$$


The DOP constant $\mathrm{C}$ depends on the semiconductor material, and it has been reported $^{5}$ that $\mathrm{C}=\mathrm{C}=50+/-10$ for GaAs. Thus, a positive DOP signal indicates that the crystal deformation is locally more compressive (or less tensile) in the x-direction than in the z-direction for the case of the (110) cross-section measurements.

We scanned the samples with a step of $0.5 \mu \mathrm{m}$ and a laser spot diameter of the order of a micrometer. The sensitivity of this technique to local strains is very high; strains as low as $10^{-5}$ can produce detectable DOP-PL signals. Thus, we can measure the anisotropic stress associated with a precision of the order of MPa.

\section{Top surface measurements}

Figure 10 shows DOP-PL measurements performed from the top surface across the stripe on a GaAs sample.

Figure 10: DOP-PL top surface GaAs for two different $\mathrm{SiN}_{\mathrm{x}} 20 \mu \mathrm{m}$ stripes (initial residual stress before etching: $285 \mathrm{MPa}$ tensile in red (50 W) and -293 MPa compressive in blue $(130 \mathrm{~W})$ ) deposited by a CCP reactor on a GaAs substrate.

Due to the limited penetration of the excitation laser, the PL signal collected in this configuration is a weighted average of the PL signal in the $100 \mathrm{~nm}$ absorption depth in the substrate material beneath the surface. The stripes have widths in the $\mu \mathrm{m}$ range (e.g., 20 $\mu \mathrm{m}$ in the case shown in fig. 10) and lengths in the mm range. This allows us to consider these stripes as infinite in length from the point of view of the strain tensor ${ }^{12}$. For a stripe that is infinite along the y-direction, it has been shown that the plane strain approximation in the $(\mathrm{x}, \mathrm{z})$ plane is valid for these samples ${ }^{12}$. Therefore $\varepsilon_{y y}$ can be considered negligible. 
Consequently, for the top surface measurements, a positive DOP-PL signal indicates perpendicular compressive strain. . Sharp peaks can be observed near the stripe edges, with opposite signs inside versus outside the stripe. This behavior of the perpendicular strain is the signature of the discontinuity occurring after etching the stressor films and was first analyzed more than thirty years ago in the framework of the edge force model ${ }^{24}$. This model was further sophisticated, considering that the stress in the thin films undergoes relaxation near the edges (see discussion in ${ }^{12}$ ). Other interesting features are revealed by the DOP-PL line scans in fig. 10. First, the DOP-PL signal remains finite near the stripe center. This shows that the strain cannot be considered biaxial near the stripe center, even if this stripe is "broad". Second, the perpendicular strain propagates in the semiconductor outside the stripe over distances of several tens of $\mu \mathrm{m}$. 


\section{Cross-section measurements}

In this part, we illustrate the use of cross-section mapping with the DOP-PL technique beneath stripes with different widths and residual stresses. After carefully cleaving the sample through the $\mathrm{SiN}_{\mathrm{x}}$ stripe, we performed measurements from the crosssection to investigate the strain distribution induced by the stressor stripe.

Figure 11: DOP-PL cross-section of GaAs for two different $\mathrm{SiN}_{\mathrm{x}}$ stripes $(20 \mu \mathrm{m}$ stripe in tension at $164 \mathrm{MPa}$ (a) and $50 \mu \mathrm{m}$ stripe in compression at $-280 \mathrm{MPa}$ (b)) deposited within the CCP reactor on GaAs substrates.

Interestingly, fig. 11 shows that the anisotropic deformation in the semiconductor bulk remains significant to more than 10 microns in-depth for both the $20 \mu \mathrm{m}$ wide tensile stripe and the $50 \mu \mathrm{m}$ wide compressive stripe. However, the sign of the residual stress in the dielectric thin film reverses the sign of the anisotropic strain.

\section{Finite element simulations}

A mathematical description of the strain effects produced by stressor films is required to calculate the modifications expected from strain engineering using such films and further to predict the changes occurring on photonic devices. In order to have an efficient tool for the design of photonic components, we chose a finite element approach. Different sets of differential equations were included to account for linear elasticity for the different materials involved (semiconductor substrate and dielectric stripe stressor) and for 
thermal expansion of the different materials since the thin films are deposited above room temperature.

We used COMSOL Multiphysics ${ }^{\circledR}$ for our numerical approach to the coupling between different mechanisms of deformation. In addition to this choice, an important issue is choosing between a two-dimensional (2D) versus a three-dimensional (3D) simulation. When the designed components have a dimension that is "long enough" (such as stripes whose length is of the order of at least 100 times the perpendicular dimensions - width and thickness), the $2 \mathrm{D}$ with plane strain assumption ${ }^{25}$ is appropriate. It allows for an accurate calculation of local materials' properties affected by stress (such as the refractive index) in any cross-section. We have checked the validity of the 2D simulation for long devices such as stripe stressors at the surface.

After choosing the adequate configuration, the next step is translating the state of mechanical stress in the thin film into the numerical simulations. Different routes have to be taken, depending on what we know about the origin of stress (intrinsic stress due to the details of the deposition process itself or stress due to the coefficient of thermal expansion (CTE)) and the geometrical details of the device being considered. To illustrate this consideration, let us take two simple cases and comment on the possible choices:

1) Stress engineering based on a stripe stressor thin film at the semiconductor surface (such as illustrated in the experimental results in figs. 10 and 11): we can either assume that the strain field results from the cooling down of the sample comprising two materials with different CTEs or assume that etching was performed at room temperature through a thin film with initial built-in stress. The second assumption seems more physically realistic since the cooling 
down step is performed before etching the stripe. However, we have checked that both assumptions yield very similar strain/stress distributions. For the second assumption, we have defined the difference in CTE in such a way that the biaxial thermal stress is equal to the initial built-in stress.

2) Evaluation of the effect of deposition of a thin film dielectric layer on top of a device with 3D structuration, such as an etched semiconductor stripe: in this case, the only way we can run a simulation is through assuming different CTEs. However, for this to be valid, the mechanical properties of the dielectric thin film need to be the same on the horizontal surfaces and on the etched vertical walls (for an etched semiconductor stripe with vertical walls, for example), which is difficult to check experimentally.

We have tried validating our numerical simulation approach by comparing it with the DOP-PL profiles and maps. In the following, the COMSOL simulations were performed using a two-dimensional plane strain model with standard free surface conditions and prescribed displacements. We have considered the stress in the thin film assuming an initial stress condition (bi-axial stress equal to the built-in stress deduced from the curvature measurements). We took the elastic properties for the GaAs substrate from the literature ${ }^{26}$ and our experimental determination (see section II) for the deposited $\mathrm{SiN}_{\mathrm{x}}$ thin film.

\section{A. Comparison of simulations with DOP-PL line scans on the top surface:}

We cannot use equation 4 directly because the normal deformations $\varepsilon_{x x}$ and $\varepsilon_{y y}$ vary (strongly) along the vertical dimension $\mathrm{z}$ (see fig. 9 for the $\mathrm{x}, \mathrm{y}$, and $\mathrm{z}$ axes). A generalized 
formula of DOP-PL, taking into account the penetration depth of the excitation laser beam, has been proposed and validated against experimental data ${ }^{12}$ using a generalized analytical model for the deformations. However, applying this formula in the framework of our numerical simulations performed with COMSOL Multiphysics, even in the 2D approach, revealed computationally intensive. To provide a simple comparison of our simulation approach with the experimental data from the top surface, we applied equation 4, taking the values $\varepsilon_{x x}$ calculated at the penetration depth of the excitation laser beam at $635 \mathrm{~nm}$. This penetration depth is defined as $\frac{1}{\alpha}$ where $\alpha$ is the absorption coefficient. This approximation is validated because the material around this penetration depth has the highest contribution to the DOP-PL signal, taking into account the strong variation of $\varepsilon_{x x}$ as a function of $\mathrm{z}$ close to the surface and the $\mathrm{z}$-dependence of the incoming laser excitation. $\varepsilon_{y y}$ was taken to be zero, as explained above. The resulting experimental and numerical line scans are shown in figure 12. As can be seen, the agreement is satisfactory. (determination coefficient $\mathrm{R}^{2}=0.78$ ).

Figure 12: A comparison of DOP-PL simulations with DOP-PL line scans on the top surface of a $20 \mu \mathrm{m} \mathrm{SiN}_{\mathrm{x}}$ stripe with $164 \mathrm{MPa}$ tensile stress.

\section{B. Comparison of simulations with DOP-PL maps on the cleaved surface:}


Figure 13 shows a simulation of the DOP-PL signal from the cross-section. For this configuration, the problem of the depth-dependence of the normal deformations $\varepsilon_{x x}$ and $\varepsilon_{z z}$ does not occur if one assumes that the cleaved surface only modifies elements of the strain tensor with a component along the y axis. Fig. 11 shows a comparison of our experimental and simulated results for the DOP-PL on cleaved cross-sections in areas close to $\mathrm{SiN}_{\mathrm{x}}$ stripes with different widths and built-in stresses; we performed the simulation to compare with the experimental maps of fig. 11.

Figure 13: A comparison of DOP-PL simulations with experimental DOP-PL for two different $\mathrm{SiN}_{\mathrm{x}}$ stripes, a $20 \mu \mathrm{m}$ stripe in tension $164 \mathrm{MPa}$ (a) and its simulation (c), and a $50 \mu \mathrm{m}$ stripe in compression $-280 \mathrm{MPa}$ (b) and its simulation (d), on GaAs substrates.

Fig. 13 shows details of the simulated DOP-PL signal, which are not all identified on the experimental map, especially at the edges. We attribute this to the limited spatial resolution $(\sim 1 \mu \mathrm{m})$ of the experimental DOP-PL maps. We notice good agreement with the experimental mapping in fig 13 (a) and (b). The anisotropic deformation in the semiconductor bulk remains significant more than 10 microns in depth. 


\section{IV.DISCUSSION}

The experiments described in this paper aimed to show how important it is to control the deposition conditions during the $\mathrm{SiN}_{\mathrm{x}}$ PECVD process to produce stressor layers and how the built-in stress in $\mathrm{SiN}_{\mathrm{x}}$ thin films affects the underlying GaAs substrate.

First, we have controlled the built-in stress in our $\mathrm{SiN}_{\mathrm{x}}$ thin films by tuning the deposition power of the CCP and ECR PECVD systems. The built-in stress was deduced from wafer curvature measurements. We observed that the deposition power affects the built-in stress of the thin films differently in the two systems. Therefore, a better understanding of the residual stress during the growth of thin films on semiconductor substrates is required. We assume that the changes in built-in stress are mainly due to microstructural and/or chemical bonding modification within the deposited films resulting from the ion bombardment ${ }^{13}$ during the deposition. We assessed the thin films' refractive index and absorption from spectroscopic ellipsometry and the hydrogen incorporation from FTIR measurements to investigate the microstructure of the films. We assume the porosity of our amorphous films constant since the refractive index does not change significantly; however, the deposition power influences the defects concentration in the $\mathrm{SiN}_{\mathrm{x}}$ films. As discussed $\mathrm{in}^{26}$, the main defects in amorphous $\mathrm{SiN}_{\mathrm{x}}$ films are the $\mathrm{Si}$ and $\mathrm{N}$ dangling bonds. We measured an increase in the optical band gap at high deposition power, which we attribute to a decrease of deep states associated with dangling bonds. Since there is enough hydrogen in the mixture to passivate all the dangling bonds, we assume that the hydrogen concentration in the films determines the optical bandgap. In the FTIR results, we noticed that at low deposition power, the films tend to be more hydrogenated, which leads to a lower optical bandgap and more tensile residual stress. We have measured the mechanical 
properties of the thin films (mainly bi-axial Young's modulus) from nano-indentation and measurements of the shape of microbeams after partial release of the films from the substrate. The Young's modulus values deduced from nano-indentation measurements appear higher than those deduced from the microbeams elongation, except for thick films, where the effect of substrate interaction on the nano-indentation measurements is less significant. However, the Young's modulus difference between these two methods was expected because they use different principles. The nano-indentation induces elastic and plastic deformation on the thin films, whereas the microbeam technique does not apply any external stress or deformation to the films. We assume that other reasons may explain this difference, such as the impact of TMAH on the $\mathrm{SiN}_{\mathrm{x}}$ microbeams' microstructure. As discussed $\mathrm{in}^{27}$, the compressive built-in stress would also affect the nano-indentation results by increasing the Young's modulus values. As a matter of fact, the estimation of $\mathrm{SiN}_{\mathrm{x}}$ films' Young's modulus using different methods is not trivial and deserves more detailed studies in the future.

Second, the $\mathrm{SiN}_{\mathrm{x}}$ thin films were structured into elongated stripes by optical lithography and etching. The stripes generate a strain field in the underlying substrate with strong spatial modulation, especially near the edges. There is a clear correlation between this controlled built-in stress and the resulting local deformation in the semiconductor material. We determined the strain field beneath the stripes experimentally using spatially resolved analysis of the degree of polarization of the photoluminescence. The simulation results, using finite element tools, agreed with the experimental measurements and could be used to design devices such as photo-elastic waveguides and explain the effects observed by manufacturers of such devices. We chose not to cover too many examples of 
such studies in this short review; however, we give references where the reader can find all the necessary details.

Our approach to the control and characterization of stress presented in this paper should prove very useful in the strain engineering of photonic devices using stressor layers deposited by PECVD systems.

\section{CONCLUSION}

In this work, we first focused on the deposition techniques themselves (standard CCP- PECVD and ECR-PECVD) to obtain the best possible control of the dielectric thin films (structure and built-in stress). Then, we described the results of physical characterization of the thin films themselves using VASE, FTIR, nano-indentation, and profilometry. We also characterized the semiconductor material near the dielectric thin film structure using DOP-PL. Some of the deposition and characterization techniques were developed in our laboratories, allowing us to go beyond standard approaches. The third focus is on modeling the behavior of the different thin film systems investigated, especially the induced mechanical stress distribution into semiconductor materials by the presence of thin-film dielectric structures. Several approaches were developed for modeling. However, we chose to investigate only one example in this paper. 


\section{ACKNOWLEDGMENTS}

This work is supported by the France Canada Research Fund 2018 program. The authors thank M. Mokhtari and P. Pagnod-Rossiaux (3SP Technologies, France) for providing some of the samples. The authors also thank the NanoRennes platform belonging to RENATECH+ (the French national network of facilities for micronanotechnology) for access to sample preparation and processing equipment.

\section{DATA AVAILABILITY}

The data that support the findings of this study are available from the corresponding author upon reasonable request.

\section{REFERENCES}

${ }^{1}$ M. Huang, Int. J. Solids Struct. 40, 1615 (2003).

${ }^{2}$ W.N. Ye, D.X. Xu, S. Janz, P. Cheben, M.J. Picard, B. Lamontagne, and N.G. Tarr, J. Light. Technol. 23, 1308 (2005).

${ }^{3}$ Q.Z. Liu, F. Deng, L.S. Yu, Z.F. Guan, S.A. Pappert, P.K.L. Yu, S.S. Lau, J.M. Redwing, and T.F. Kuech, J. Appl. Phys. 78, 236 (1995).

${ }^{4}$ A.R. Adams, IEEE J. Sel. Top. Quantum Electron. 17, 1364 (2011).

${ }^{5}$ D.T. Cassidy and M.A. Fritz, Appl. Opt. Vol. 43, Issue 1, Pp. 160-166 43, 160 (2004).

${ }^{6}$ L. ZH, Z. H, W. S, A. DC, and W. JW, Phys. Rev. B. Condens. Matter 45, 4131 (1992).

${ }^{7}$ G. Beaudoin, G. Fishman, I. Sagnes, M. de Kersauson, M. El Kurdi, P. Boucaud, R. Jakomin, S. David, S. Sauvage, and X. Checoury, Opt. Express, Vol. 19, Issue 19, Pp. 17925-17934 19, 17925 (2011).

${ }^{8}$ Q.Z. Liu, X.B. Mei, L.S. Yu, C.W. Tu, and S.S. Lau, MRS Online Proc. Libr. 1995 3791 379, 303 (2011).

${ }^{9}$ H. Rho, H.E. Jackson, and B.L. Weiss, J. Appl. Phys. 90, 276 (2001).

${ }^{10}$ E. Lea and B.L. Weiss, IEE Proc. Optoelectron. 147, 123 (2000).

${ }^{11}$ G. Abadias, E. Chason, J. Keckes, M. Sebastiani, G.B. Thompson, E. Barthel, G.L. Doll, C.E. Murray, C.H. Stoessel, and L. Martinu, J. Vac. Sci. Technol. A Vacuum, Surfaces, Film. 36, 020801 (2018).

${ }^{12}$ S. Gérard, M. Mokhtari, J.P. Landesman, C. Levallois, M. Fouchier, E. Pargon, P. Pagnod-Rossiaux, F. Laruelle, A. Moréac, B. Ahammou, and D.T. Cassidy, Thin Solid Films 706, 138079 (2020).

${ }^{13}$ J.A. Taylor, J. Vac. Sci. Technol. A Vacuum, Surfaces, Film. 9, 2464 (1998).

${ }^{14}$ M. Lorenzoni, J. Llobet, F. Gramazio, M. Sansa, J. Fraxedas, and F. Perez-Murano, J. Vac. Sci. Technol. B, Nanotechnol. Microelectron. Mater. Process. Meas. Phenom. 34, 06KK02 (2016). 


\footnotetext{
${ }^{15}$ M. Boudreau, M. Boumerzoug, R. V. Kruzelecky, P. Mascher, P.E. Jessop, and D.A. Thompson, Can. J. Phys. 70, 1104 (1992).

${ }^{16}$ G.G. Stoney and G. Gerald, Proc. R. Soc. London. Ser. A, Contain. Pap. a Math. Phys. Character 82, 172 (1909).

${ }^{17}$ J. Tauc, R. Grigorovici, and A. Vancu, Phys. Status Solidi 15, 627 (1966).

${ }^{18}$ H. Fujiwara, Spectroscopic Ellipsometry: Principles and Applications (John Wiley \& Sons, 2007).

${ }^{19}$ D. V. Tsu, G. Lucovsky, and M.J. Mantini, Phys. Rev. B 33, 7069 (1986).

${ }^{20}$ A. Tarraf, J. Daleiden, S. Irmer, D. Prasai, and H. Hillmer, J. Micromechanics Microengineering 14, 317 (2004).

${ }^{21}$ W.C. Oliver and G.M. Pharr, J. Mater. Res. 19, 3 (2004).

${ }^{22}$ D. Maier-Schneider, J. Maibach, and E. Obermeier, J. Microelectromechanical Syst. 4, 238 (1995).

${ }^{23}$ M.A. Fritz and D.T. Cassidy, Microelectron. Reliab. 44, 787 (2004).

${ }^{24}$ S.M. Hu, Appl. Phys. Lett. 32, 5 (1978).

${ }^{25}$ S. Timoshenko and J.N. Goodier, Theory of Elasticity" McGraw-Hill Book Company (1951).

${ }^{26}$ J. Robertson, Philos. Mag. B Phys. Condens. Matter; Stat. Mech. Electron. Opt. Magn. Prop. 69, 307 (1994).

${ }^{27}$ A.W. Warren, Y.B. Guo, and M.L. Weaver, Surf. Coatings Technol. 200, 3459 (2006).
} 


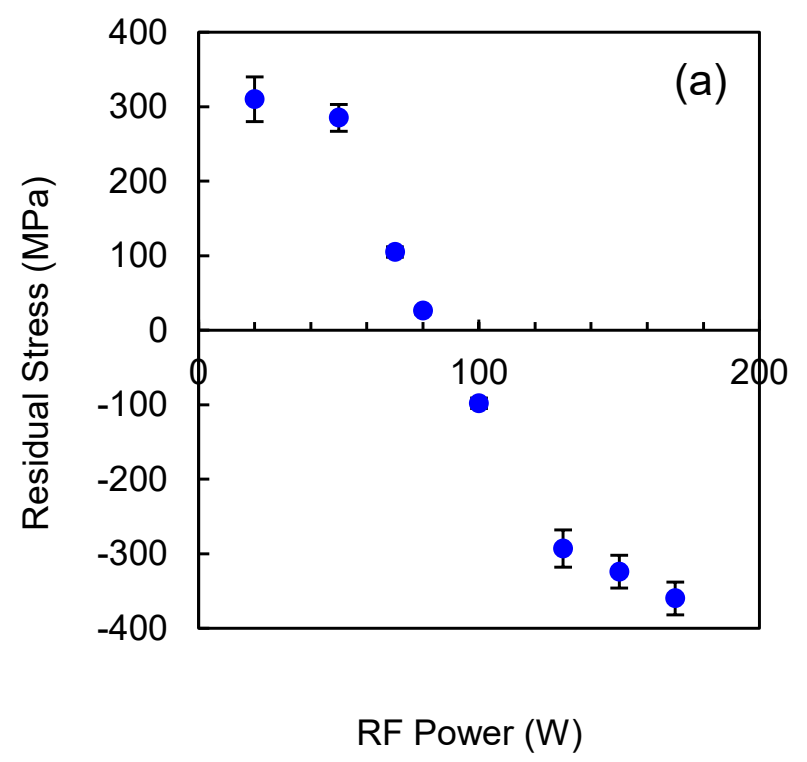




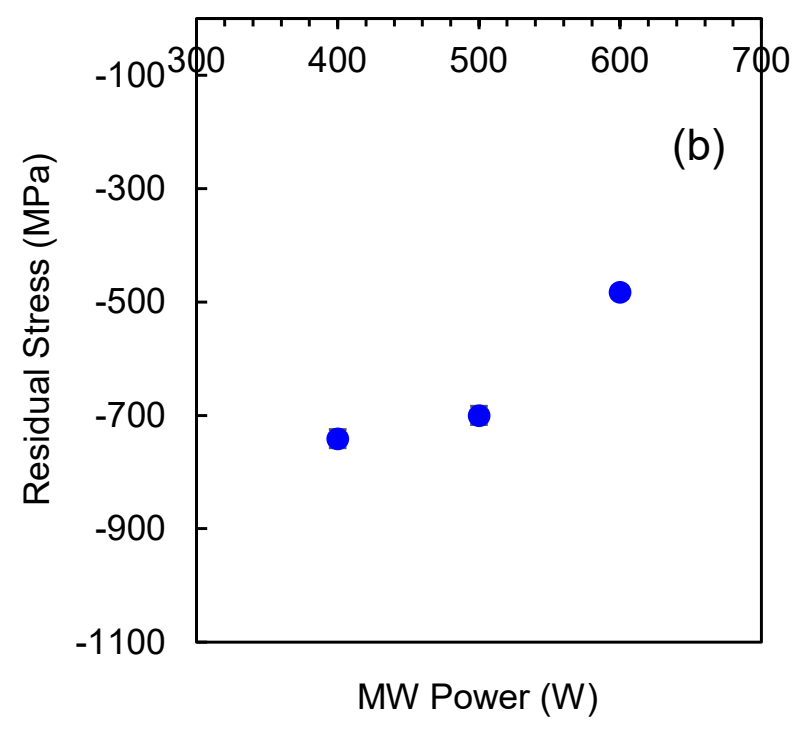




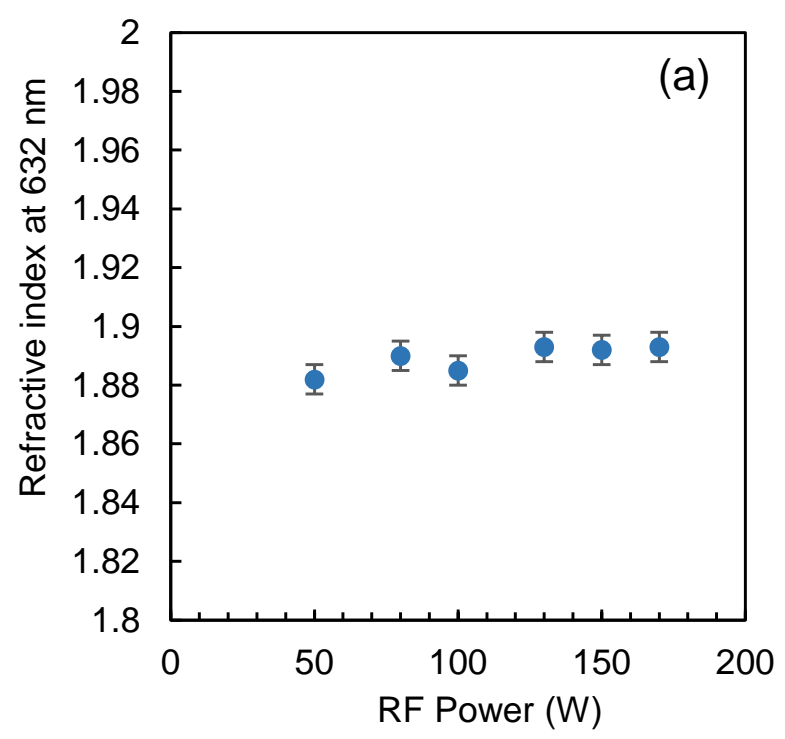




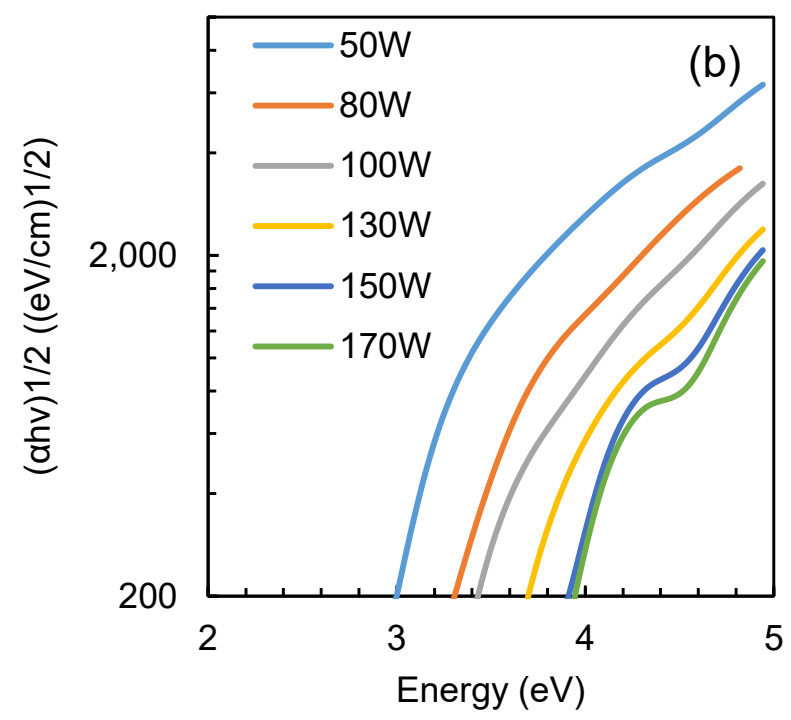



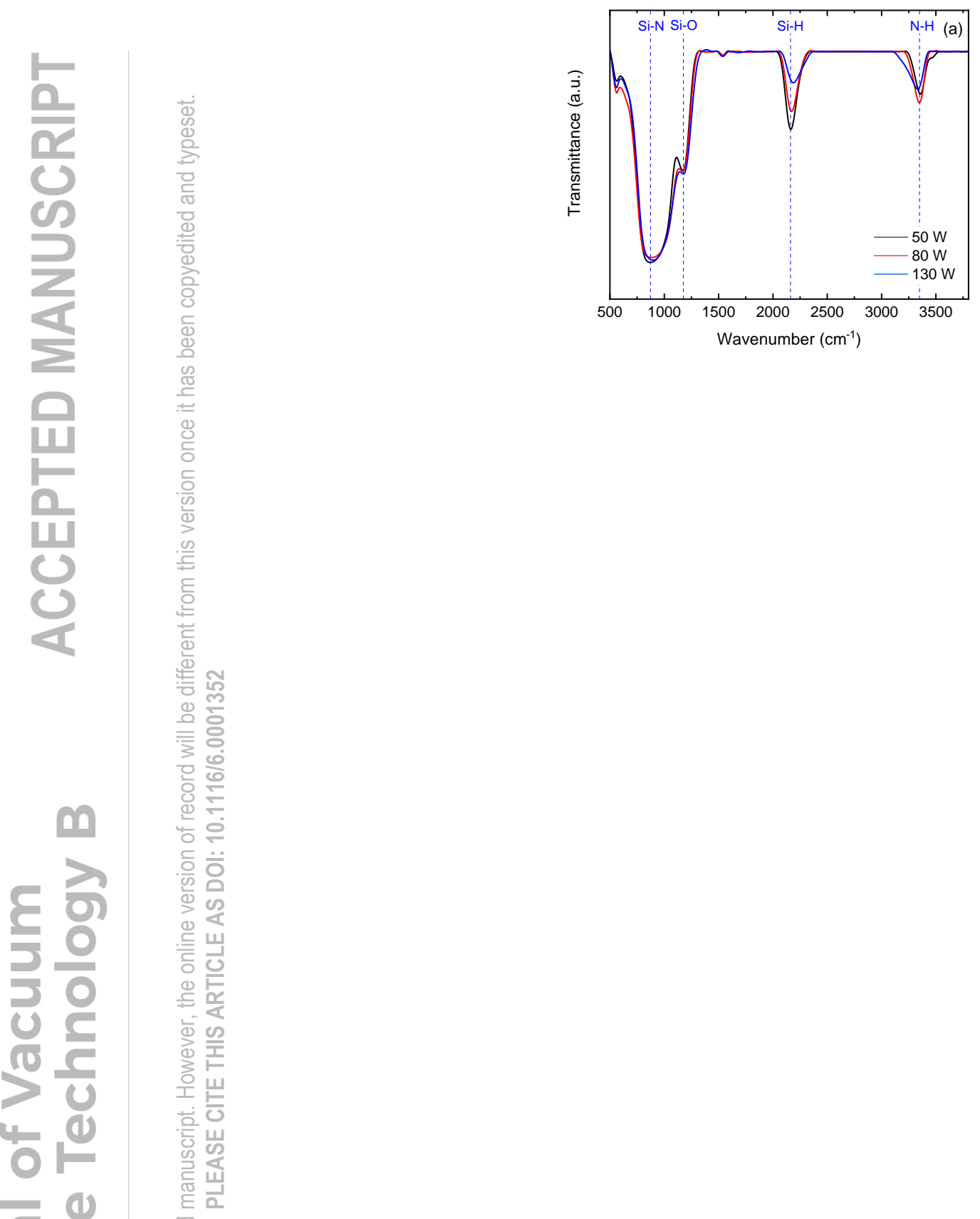

능 ำ

을

은

है

는

흥

.

更

专

딷

凹

푸

능

世

岂

1000

C

(1)

0

20

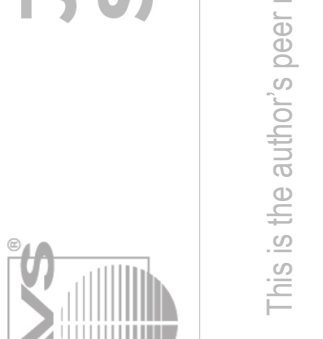




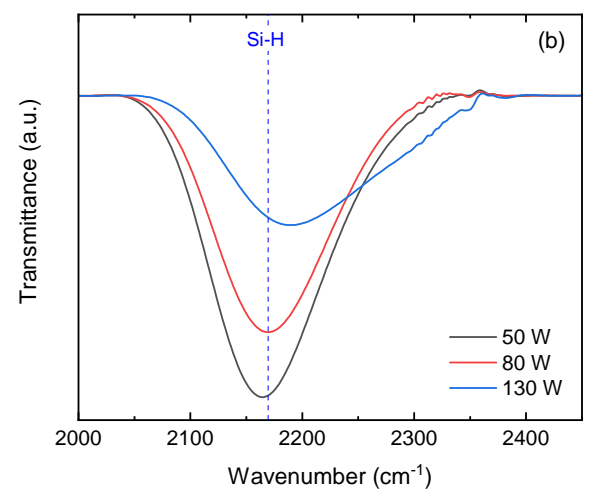




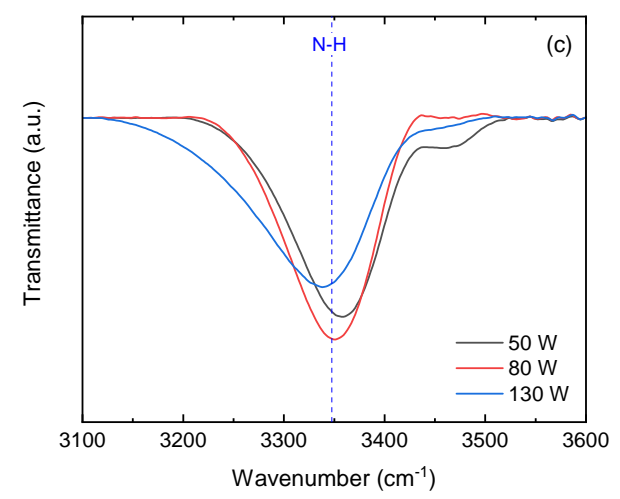




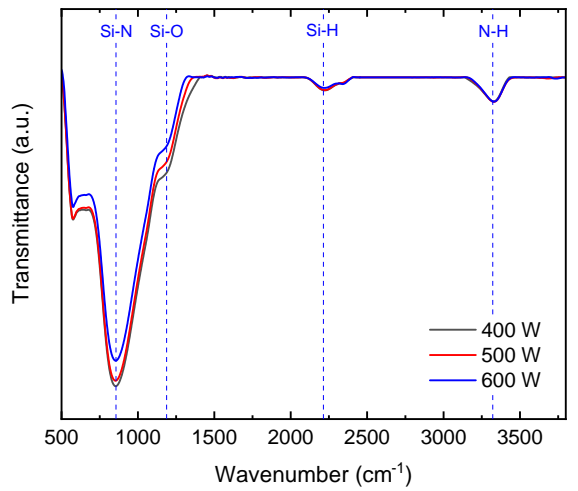

ก

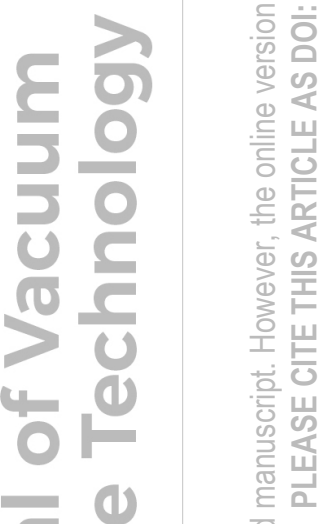

능 ำ

응ㅎㅇ

3

응 흔

일

웅

の

世

要

눈

韦

엉

崖

풀

믐

1000

C

(1)

0

20

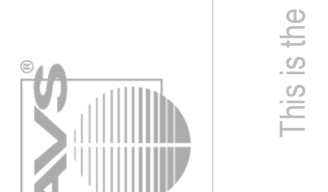




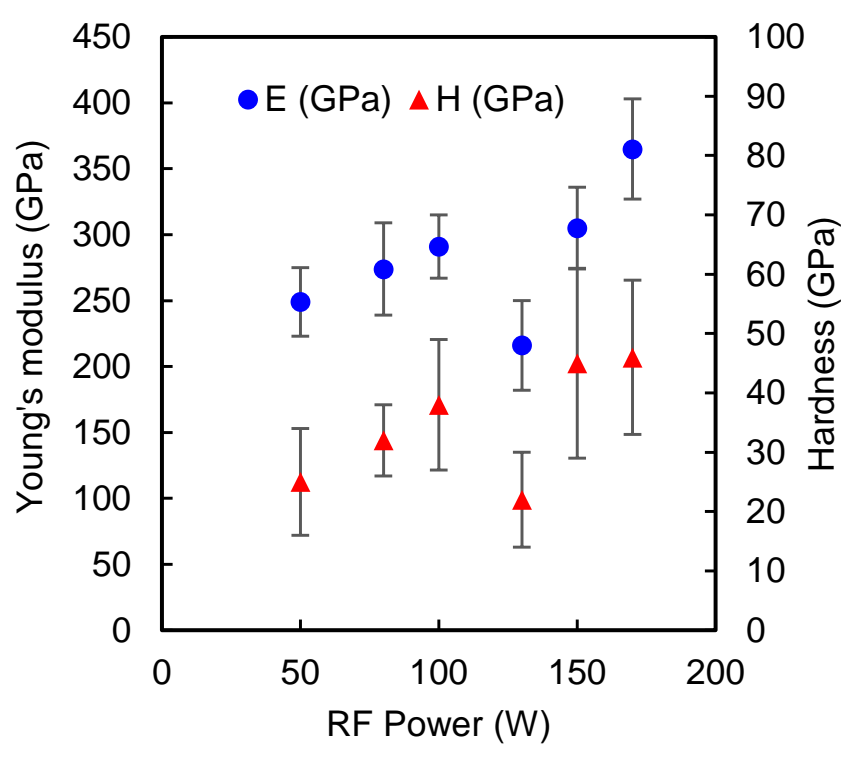




\section{TMAH 5\%}

SiN

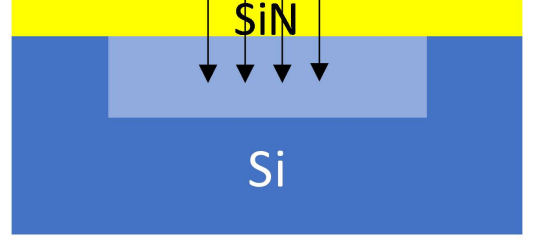

SiN

Si

n

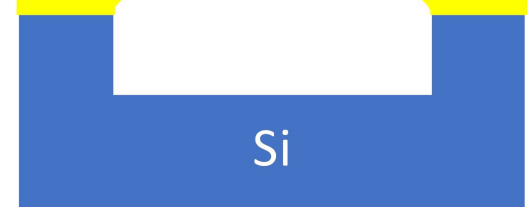

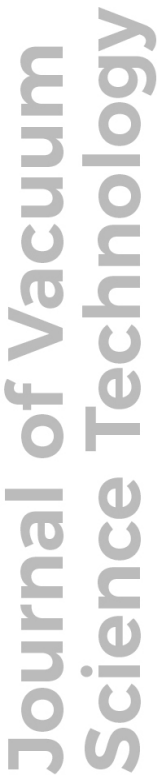

雾 땡

응

응 음

능 흥

드응

힝

(1)

핌

닫 만

히롵

오삐

흥응

는

담

ह $\vec{\square}$

옴

(o) 


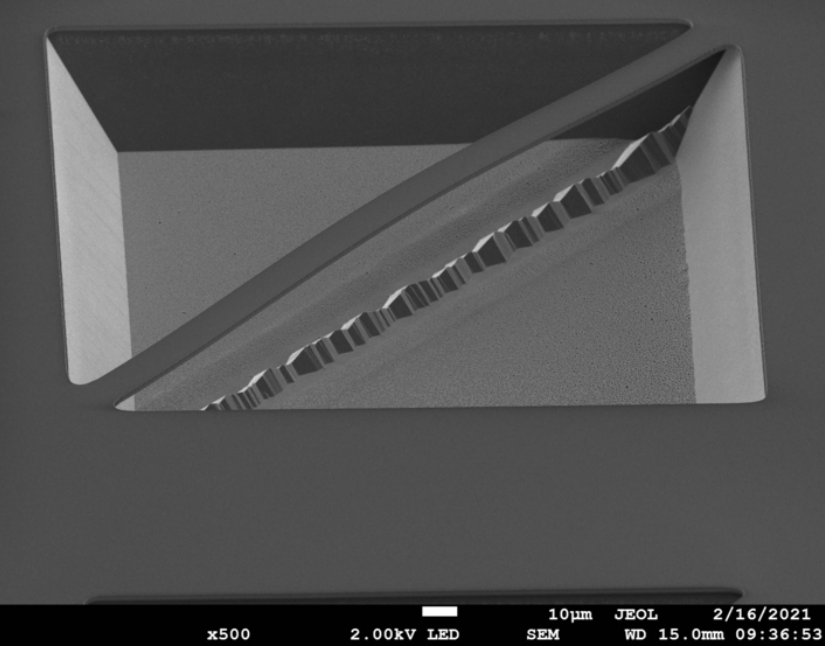

กิ

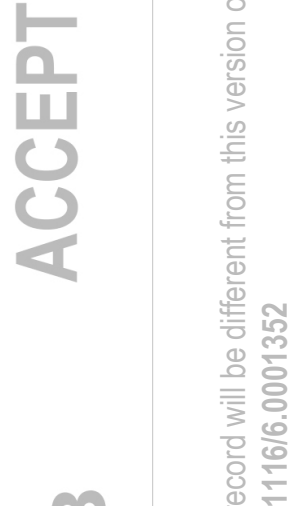

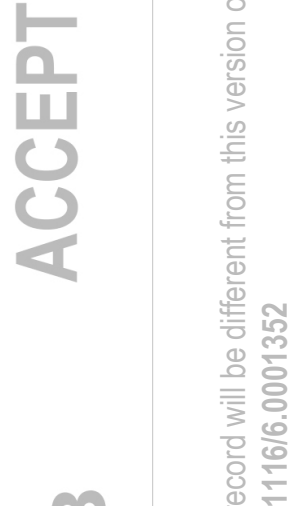

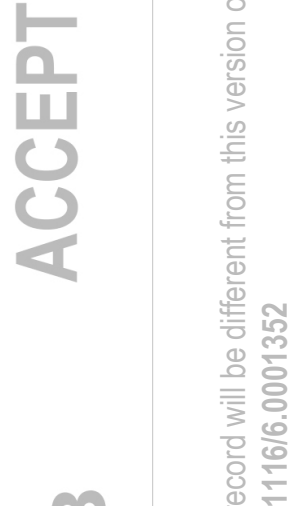

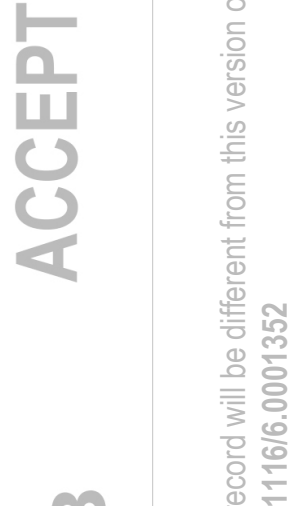

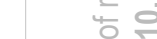

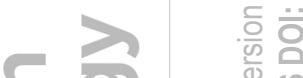

다 01 क

00 亭殅

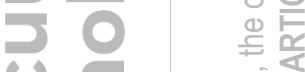

(U) $E$

10 C

10 오쁜

(1) (1)

( 1

(1) ह है

1000

(c)

(4)

(1)

01

$+2$

嵌

端

x500

$.00 \mathrm{kV}$ LED 


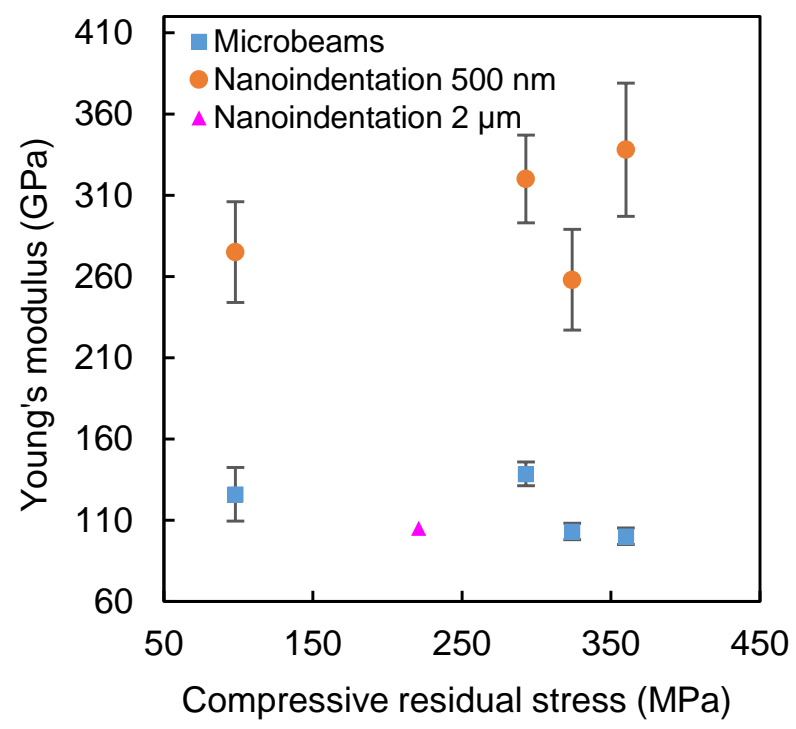




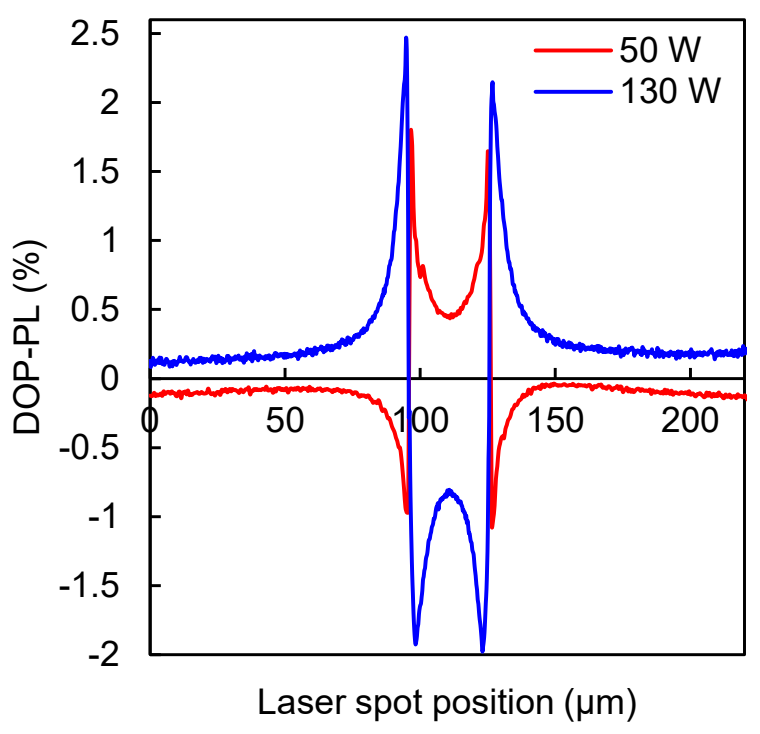



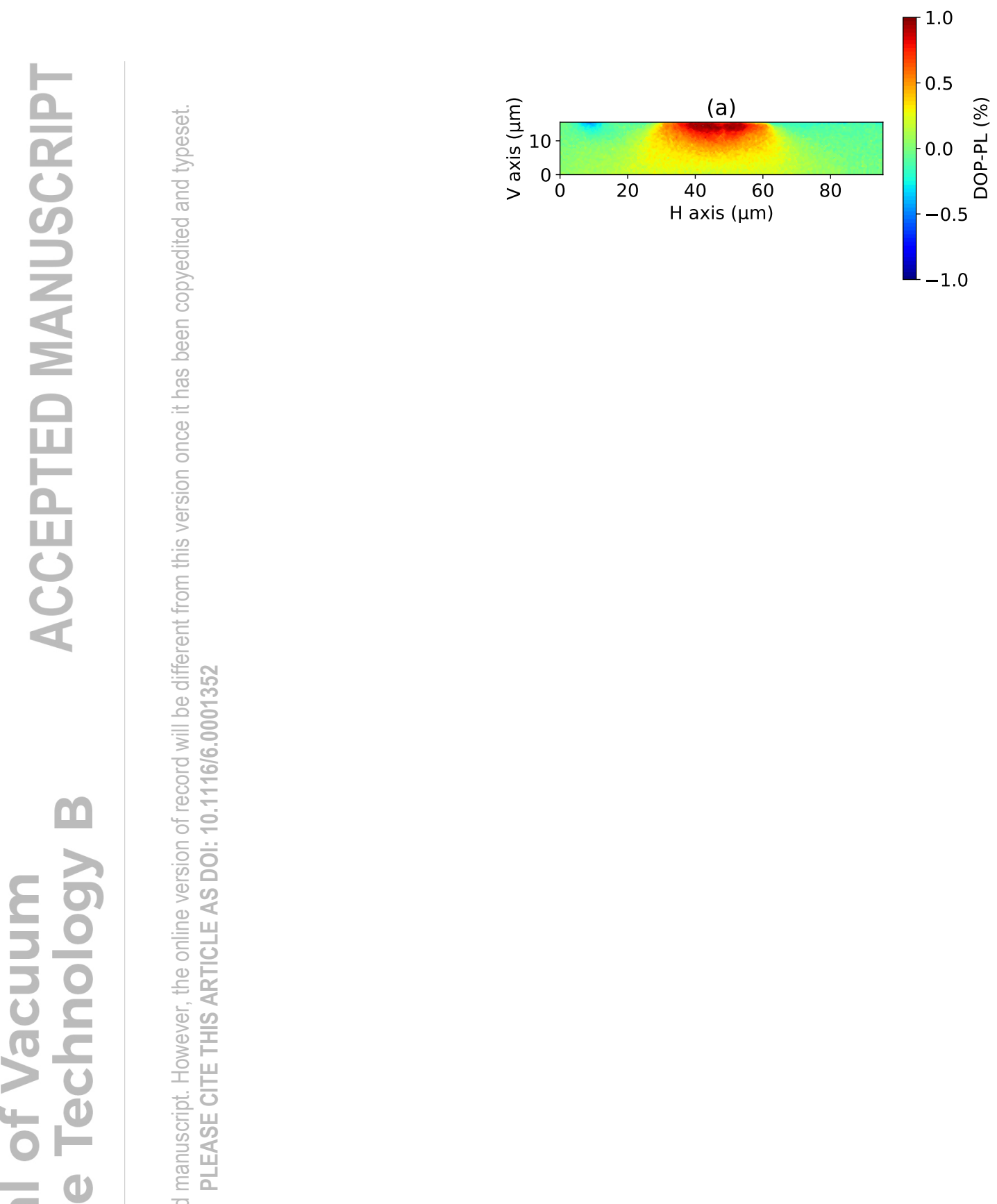

$\begin{array}{ll}10 & 0 \\ 0 & 0 \\ 0 & 0 \\ 0 & 0\end{array}$

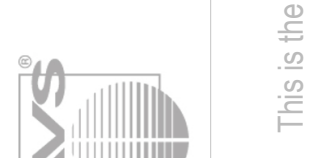



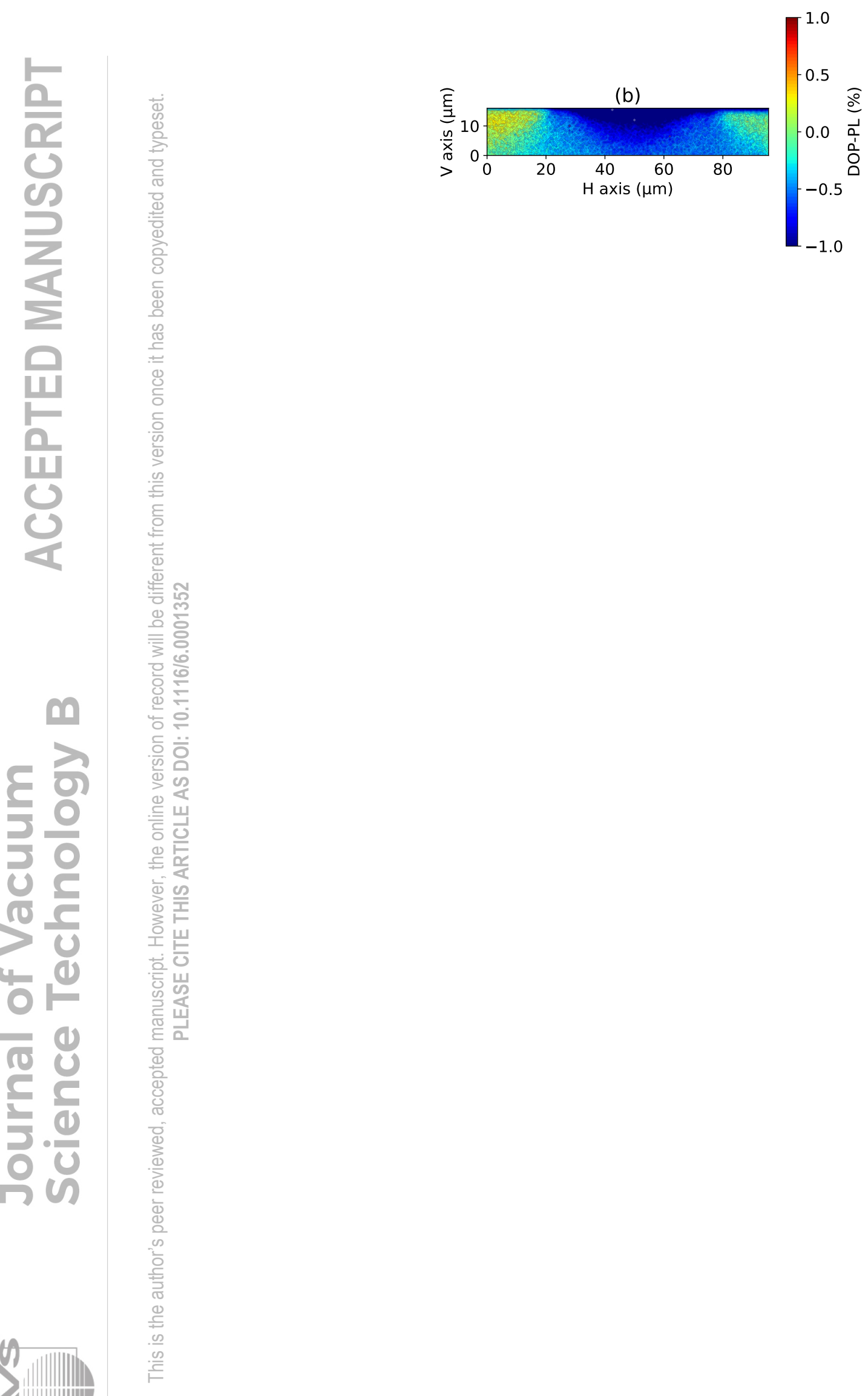


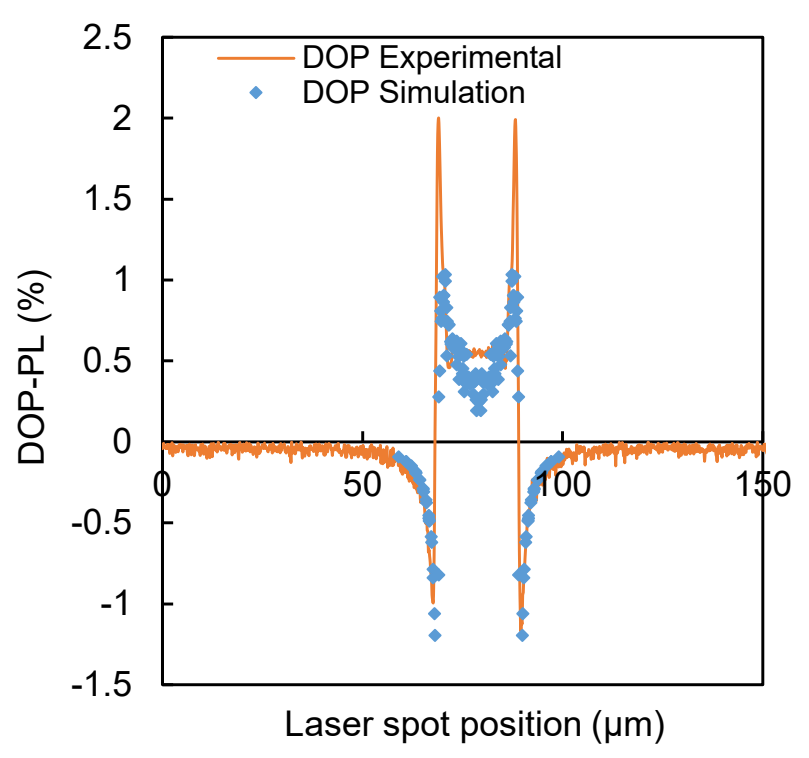



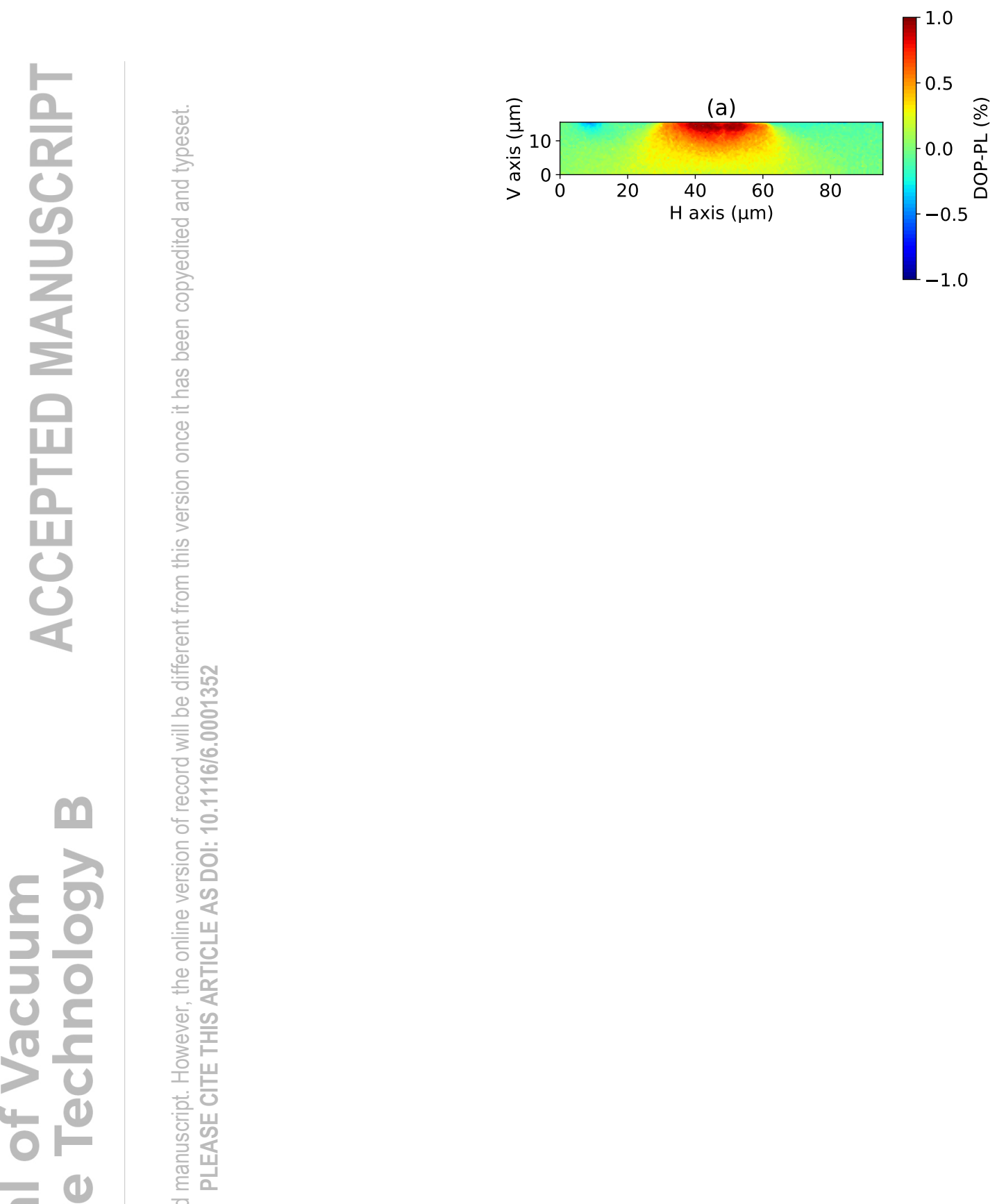

$\begin{array}{ll}10 & 0 \\ 0 & 0 \\ 0 & 0 \\ 0 & 0\end{array}$

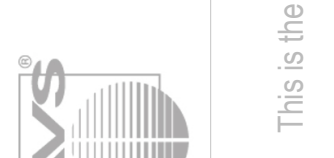



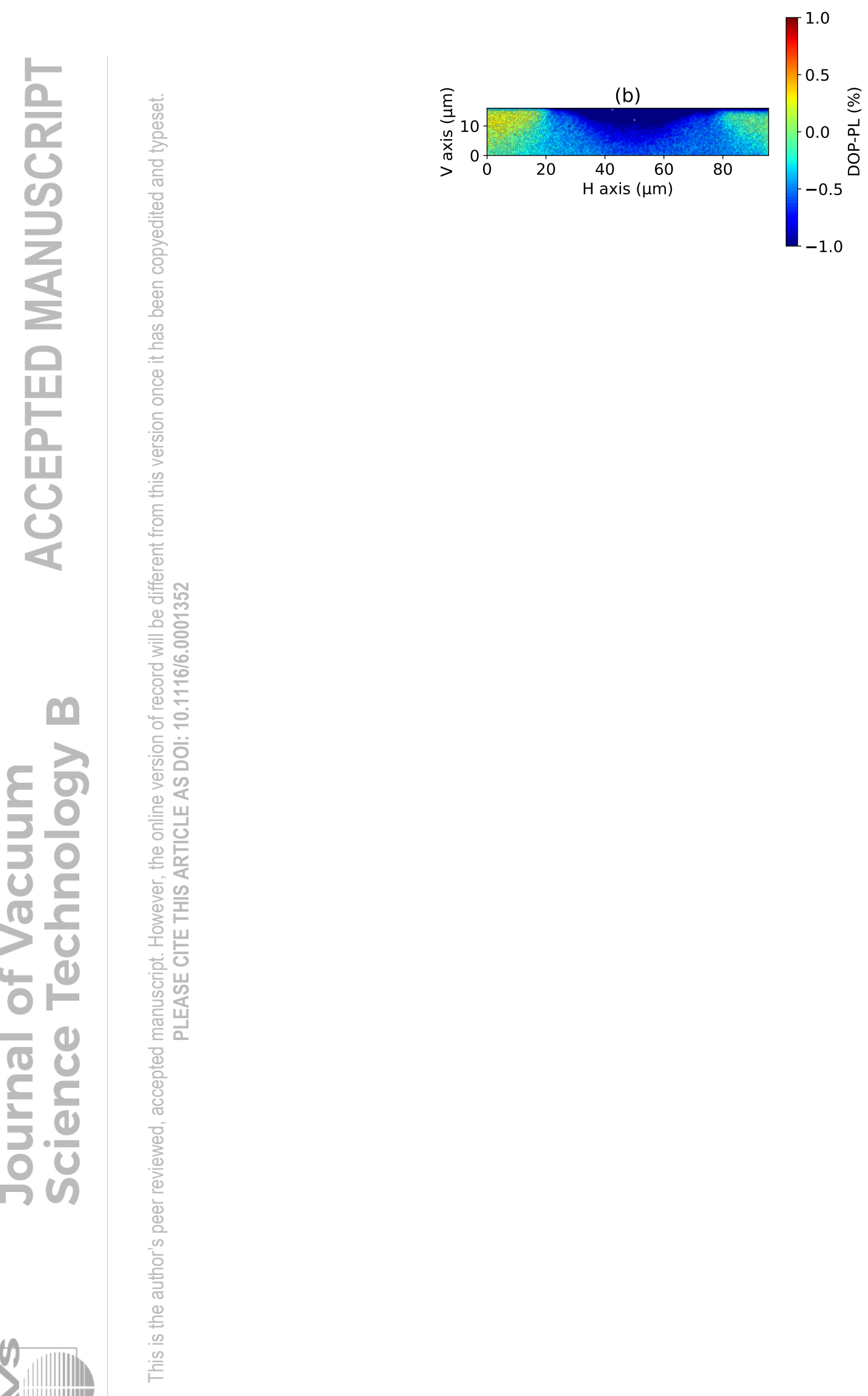


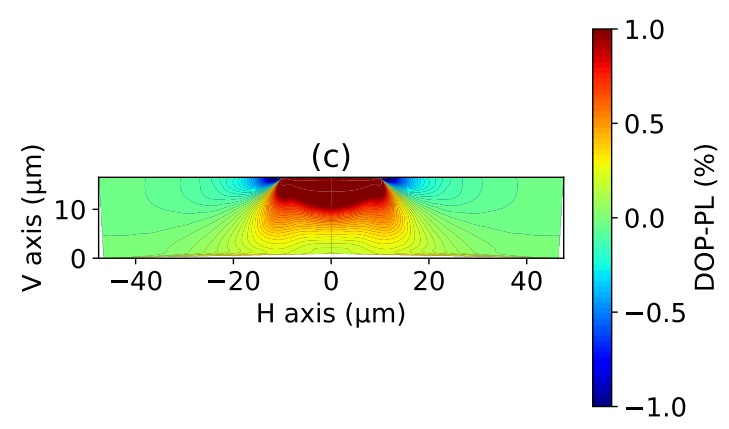

กอ

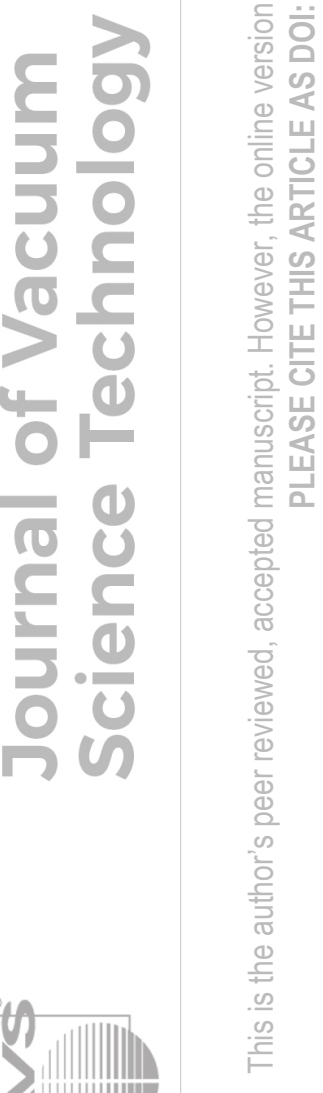




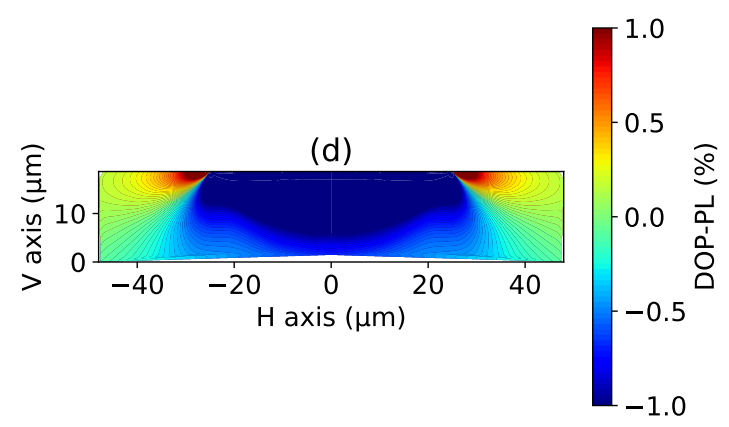

ก

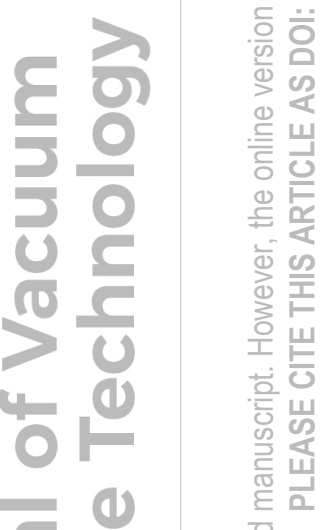

10 10

ํํำ

응

은

웜둥

은

.

安

里

오 픈

㟧 